\title{
EVARISTO VALLE: COR, FIGURA E LIRISMO
}

Maximiliano Gutiez ${ }^{1}$

\section{Resumo}

Evaristo Valle (1873-1951), pintor asturiano hoje pouco conhecido, teve um papel singular e de relevo no Modernismo espanhol. Sua obra reflete suas vivências na Paris da virada do século e também as efervescências sociais da região de Astúrias, berço dos conflitos que levaram à Guerra Civil Espanhola. Influenciado pelos grandes mestres espanhóis (Velazquez, El Greco e Goya), desenvolveu um trabalho cromático original, em que as cores adquirem valor simbólico, sugerindo interpretações líricas das composições. Transpôs para a pintura a óleo as técnicas da aquarela (como as "aguadas"), explorando com leveza os contrastes de matizes e tonais, as densidades de cor e as transparências. Seu tema principal são as figuras do povo de sua região. Mais que pessoas, EV retrata uma sociedade, recriando-a e ampliando sua potência poética.

Palavras-chave: Evaristo Valle; Modernismo Espanhol; cor e figura; simbolismo cromático.

\section{Resumen}

Evaristo Valle (1873-1951) es un pintor asturiano no muy conocido, pero tiene un papel singular en el Modernismo Español. En su obra se respira el clima parisino de la entrada del siglo XX y también las efervescencias sociales en Asturias, cuna de los conflictos que llevaran a la Guerra Civil Española. Influenciado por los grandes maestros españoles (Velazquez, El Greco e Goya), desenvolvió un original trabajo cromático, con la transfiguración de la realidad a través del color sugiriendo interpretaciones líricas en sus composiciones. Incorporó la técnica de la aguada, de la acuarela en la pintura al óleo, explorando el mundo de los contrastes de matices y tonos, el cuerpo del color y las transparencias. Su tema principal es la gente de su pueblo, su Alma Asturias. EV no pinta personas, pinta el retrato de una sociedad, recriándola y ampliando su potencial poético.

Palabras claves: Evaristo Valle; Modernismo Español; Color y figura; Simbolismo cromático.

Toda manhã bem cedo, sentado a uma grande mesa de madeira rústica na cozinha de minha avó, em meio ao vapor de uma cumbuca de leite recém-ordenhado, via a luz espreguiçar-se pela janela anunciando a chegada do dia; na parede ao lado pendia um calendário com a reprodução de uma pintura. Seduzido pela quantidade de cores, fascinavame pela composição da pintura organizada por intensos contrastes cromáticos, pelo movimento tão lúdico oferecido a meus olhos de sete ou oito anos de idade.

O título da pintura me era muito próximo. A velha e o menino, de 1918 (óleo s/ tela, $47 \times 55 \mathrm{~cm}$ ), tem como tema principal uma cena cotidiana, anedótica e trivial: uma velha e um menino ao entardecer caminham para casa. Lembrava-me das caminhadas em que minha avó me ensinava a olhar os diversos momentos com que a natureza nos brindava no decorrer do dia. Tinha ao mesmo tempo uma sensação muito próxima do medo. Havia o mistério de não entender esse momento de saída do dia e entrada da noite, a simultaneidade de luz e escuridão, a despedida do sol e a vinda das estrelas, tudo tão

${ }^{1}$ Doutorando no Departamento de Artes do Instituto de Artes da Universidade de Campinas (IA/Unicamp). 
imenso e infinito, como o grande e misterioso mundo. E, para meu assombro, tudo aquilo era representado numa pequena "janela".

A cena é sustentada por um belo trabalho de luminosidade e cromatismo. O espaço está construído em dois planos, opondo o longe e o perto por meio da luz: no alto da tela, os azuis cobalto e prússia formam os densos da noite, que se diluem ladeiras abaixo em direção à cena principal, formando progressivamente a doce claridade da tarde moribunda. Situadas entre os dois planos, as copas das árvores em amarelo saturado com manchas em cobre, simbolizando o outono, estão fincadas como estacas nos azuis escuros do céu. Os verdes escorrem pelas pradarias próximas, e um caminho de ocres e carmins envoltos em tons suaves de pêssego, confrontados com pinceladas de azul celeste, abre-se aos passos a serem dados. Ressoam os versos de Antonio Machado:

Caminhante, são pegadas / seu caminho, e nada mais; / caminhante, não há caminho, / se faz caminho ao andar. / Ao andar se faz caminho / e ao voltar a vista atrás / se vê a trilha que nunca / se há de voltar a pisar.

Abaixo dessas árvores, o dia, empurrado pelas sombras, se desvanece numa luz tênue. As duas figuras humanas distintamente enfrentam o princípio e o fim da Vida, realçados por cores contrastantes e simbólicas. No menino, rivalizam-se com a mesma intensidade tonal o alaranjado quase amarelo de suas roupas e o fundo verde do campo, constituindo assim o único ponto de atração por contraste com o resto da composição, e a cor primária ludicamente deixa entrever a ingenuidade do porvir... A velha, construída por pinceladas dos mesmos matizes das árvores, com as cores do outono, nos reporta ao término de um ciclo. Dois caminhos, um que principia e outro que se acaba, batidos por dois caminhantes lado a lado: uma cor se acende, outra se ofusca.

Esta foi a primeira pintura que seduziu meus olhos. Desde então comecei a observar tudo ao meu redor, na pequena Pandenes onde vivia (vilarejo em meio à cordilheira Cantábrica). Estava na província de Astúrias, ao norte da Espanha, berço da Reconquista (722 d.C.) e também lugar onde séculos mais tarde se dariam os primeiros conflitos que levaram à Guerra Civil Espanhola (1934-1939); a região sofreu particularmente os horrores da guerra. Em meio a tanta história, o mestre Evaristo Valle (1873-1951), originário dessa mesma Astúrias, despertava-me a curiosidade pelas cores, uma necessidade de manipulá-las, que logo se tornaria uma grande paixão pela pintura.

\section{As origens na cor}

Evaristo Valle nasceu em 1873, na cidade de Gijón (Astúrias), de uma família tradicional e abastada da região. Seu pai ocupou cargos importantes, de juiz de paz em Gijón a governador nas Ilhas Filipinas. Quando Evaristo tinha dez anos, seu pai foi nomeado em San Juan de Puerto Rico e a família se mudou ao Caribe. Suas primeiras pinturas foram feitas nesta época, sob a orientação do próprio pai, que bem cedo reconheceu e fomentou o talento do filho para o desenho e a pintura. Algo da luz caribenha de sua infância deve ter permanecido nas cores cintilantes de sua obra posterior.

O pai de Evaristo veio a falecer poucos meses depois. A família passou a viver dificuldades, entre elas a impossibilidade de proporcionar ao jovem talento uma formação artística com algum mestre pintor. De volta a Gijón, a partir de 1885, Evaristo é um adolescente que divide seu tempo entre os estudos e os trabalhos: num banco, numa refinaria de petróleo e, por fim, numa litográfica, onde esperava encontrar algo do mundo da pintura. EV almejava ser um artista da cor. Autodidata, sua formação se deu pela observação dos grandes mestres espanhóis: El Greco, Velazquez e Goya. 
Seus sonhos o levaram a Paris, para onde se mudou em 1898. Lá, Evaristo encontraria a vanguarda cultural e ideológica da época, além da possibilidade de relacionarse com artistas de inquietudes similares às suas. Neste primeiro período parisiense, EV foi tão somente um operário litógrafo. Entretanto, não deixou de perseguir suas ambições. Parte de sua formação aconteceu no contato com velhos mestres, aos quais mostra seus trabalhos - desenhos, caricaturas (algumas publicadas na revista Le Rire) e aquarelas. Um exemplo foi sua amizade com Daniel Urrabieta Vierge, o qual visitaria várias vezes. Vierge é naquele momento o seu principal interlocutor sobre Arte.

A relação de EV com Vierge estava muito ligada ao papel, principalmente como suporte para aquarelas (mas também ilustrações e litografias). Delicado e frágil, o papel exige uma mão leve, independente da força expressiva que se queira representar. Vierge, pai da ilustração moderna dos fins do século XIX, dominava essa relação mão-papel. O jovem Evaristo observava os elementos plásticos sendo tratados ludicamente pelo mestre, principalmente a luz.

Aliás, é à luz da aquarela que se deve compreender a pintura de EV. Na aquarela, tempo e espaço estão de tal maneira inseridos um no outro que é como se um espectro visível se formasse, camadas translúcidas movem-se com a água, abrindo, fechando e diluindo espaços, como os véus da noiva a mover-se a caminho do altar. Como nas aguadas, a luz é penteada ${ }^{2}$ (manipulando-se o pincel de maneira similar a quem penteia cabelos), com a delicadeza de quem quer preservar um núcleo mínimo no vasto universo, um instante na Eternidade. A partir da primeira camada - virgem, pura -, o aquarelista recita sua poesia, ora rimando, ora opondo, matizes e tonalidades, dispersa pétalas na água. EV transpõe ao óleo sobre tela este processo de constituição da luz na aquarela, e pode-se supor que a relação com Vierge o tenha auxiliado a realizar essa passagem. Enquanto superpõe capas translúcidas, reserva matizes limpos, contrastados pela cor, evidenciando assim as cores que estão na origem dos jogos cromáticos de suas pinturas. A luz será um valor plástico de máxima relevância na obra de EV, sendo, em muitos casos, construída pelo próprio trabalho com as cores.

Passada a Exposição Universal de 1900, o trabalho fica escasso em Paris e EV é obrigado a voltar a Gijón. Percebe então as limitações que sua situação social lhe impunha, e também que a litografia não satisfaria suas ânsias criadoras. O difícil era transpor a muralha social que o cercava. Em Gijón, no ano de 1902 (aos 29 anos), Evaristo decide iniciar uma aventura que não terá mais fim: buscar na pintura a sua liberdade.

De 1902 a 1905, paralelamente à pintura, EV realiza alguns trabalhos de litografia, em que se reconhece claramente a influência parisiense, pelo uso da cor, da linha e do espaço à maneira dos estereótipos e rupturas formais do Art Nouveau. Nesta mesma época, faz várias viagens a Madrid para visitar o Museu do Prado. Isso talvez explique a clara influência dos mestres pintores espanhóis nas suas pinturas desta época.

A obra de Velásquez (1599-1660), por exemplo, será uma verdadeira escola para sua pintura. No retrato de Florêncio Rodriguez del Valle (1906) (26x24 cm, óleo s/ tela), reconhece-se claramente elementos estilísticos velazquianos. O rosto é construído com pinceladas suavemente deslizadas e penteadas com delicadeza, demarcando bem $\mathrm{O}$ contraste claro-escuro, quase que forçado no contorno do rosto por uma espécie de linha, que muito se assemelha à linha utilizada na litografia. Este tipo de linha será quase uma constante em suas pinturas futuras. O fundo com o cabelo lembra muito o estilo de

2 A expressão é freqüentemente usada por especialistas no mundo da Arte para designar um tipo de pincelada velazquiana. 
Velásquez, com pinceladas penteadas diluindo o contraste tonal, que se perde com o fundo, assim como os pontos de sombreado da roupa com um branco manchado de verde, utilizando dois tipos de pincelada, uma mais densa, e outra mais fina, gerando a sensação de semitransparência. EV seduz-se por estes contrastes. Em sua obra futura, a importância encontra-se nos contrastes não tonais, mas sim de matizes, de onde ele retira a força geradora do movimento cromático, o ritmo para a poética das cores.

Em 1907 EV realiza sua primeira exposição em Gijón. Foi muito significativa, pois pôde ser respeitado e admirado como pintor. As obras expostas compreendiam desenhos, pastéis sobre papelão, caricaturas em aquarela, retratos e paisagens asturianas em óleo sobre tela. EV já tinha um reconhecimento por seu desenho muito divulgado pelo trabalho de litografia e publicações de suas caricaturas em revistas e jornais. Com essa exposição, críticas bastante favoráveis a suas pinturas foram publicadas nos diversos meios de comunicação da época.

\section{Figuras asturianas}

Entusiasmado pela boa crítica à sua primeira exposição, exaltado pelos amigos, Evaristo decide partir novamente à conquista de Paris, onde fica de 1908 a 1911. Instala-se num ateliê na rue Belloni, próximo a Montparnasse. EV está agora em posição mais cômoda, e mais rica do ponto de vista das experiências pictóricas. A sua produção neste período fica vinculada a uma série de retratos de figuras da aristocracia e alta burguesia. Uma nova vertente se abria ao artista, desta vez tudo indicava um sucesso mais promissor.

Nesta época, vemos um EV boêmio, freqüentando cafés de movimentação cultural, como o Café Dumesmil, em Montparnasse. Certa vez enfrentou, numa partida de xadrez, um russo que ficaria muito conhecido ao eclodir da Revolução Russa: Lênin. Em El orador (1917), representa a figura de um orador alçada numa plataforma, transfigurado e distinto daqueles que o ouvem, aparentemente um grupo de camponeses; a gestualidade lembra muito aquela que caracteriza Lênin em muitas fotografias da Revolução. $O$ paradeiro dessa obra é desconhecido, o que não é de se espantar, tendo em vista que EV passou até seus últimos dias na Espanha franquista: pinturas assim eram muito comprometedoras.

Nestes tempos, EV conheceu pessoalmente Ignacio Zuloaga, dentre os artistas do modernismo espanhol aquele que alcançou o maior êxito internacional. Alguns pontos comuns entre as obras destes dois artistas são na realidade representativos de toda uma geração de artistas. Sendo ambos descendentes diretos da Geração de $98^{3}$, seus mundos pictóricos buscam seu lugar em meio ao mundo de sua gente - uma gente extremamente empobrecida após o chamado desastre colonial, em que Espanha perdeu suas últimas colônias -, não para mostrar com pessimismo a crueza de suas vidas, mas sim, a grandeza de sua luta cotidiana, de onde tiram o orgulho que compõe suas terras maravilhosas. Pela força de expressão, belíssima e altamente lírica, com que tratam sua temática, ambos autores situam-se num mesmo patamar.

\footnotetext{
3 “Geração de 98" foi um importante movimento de protesto, formado por pensadores de todas as extensões culturais da sociedade espanhola, que se constituiu em reação ao desastre militar de 1898, em que a Espanha perde suas últimas colônias (Cuba e Filipinas), visando a provocar de alguma maneira uma reforma na vida nacional. Trata-se de um movimento altamente nacionalista, que, buscando novos valores no passado espanhol, descobre uma Alma espanhola. Juntamente a Ignacio Zuloaga, o poeta Antonio Machado (1875-1939) é um autor bastante representativo deste movimento.
} 
Zuloaga queria intervir na paisagem com seus pincéis. O terra-de-sombra escuro, o ocre, o siena, cores de um espaço quase desértico, constituem a grandeza de uma dor intrínseca aos habitantes de Castela. De maneira similar, EV utiliza os diversos amarelos, azuis e verdes, cores descobertas em sua terra asturiana, na construção de suas figuras. As cores cintilantes e contrastadas por excelência criam uma sensação de superficial alegria cromática; as figuras são reflexivas e conformadas, sem qualquer exagero tendencioso, mas sem tampouco ocultar a situação penosa que vivem neste momento. Poucas vezes a devoção de artistas pela cor foi tão representativa: enaltecem as cores que geram os espaços, como símbolos ou bandeiras de uma batalha pela sobrevivência. Por essa razão, podemos diferenciá-los do gosto arraigado na Paris da época, com o decadentismo europeu, caracterizado por uma visão pessimista de ressonâncias sociais, em que se enquadram movimentos como o expressionismo alemão dos grupos Die Brüche e Der Blauer Reifer. Em vez disso, o trabalho cromático de EV e Zuloaga provém de um orgulho patriótico e simbólico; tratando as cores como num poema de amor, enxergam a beleza onde uma grande tristeza domina. Da angústia pela impotência diante dessa triste realidade, nasce um olhar transformador, que mostra o drama cotidiano, mas também a sensibilidade das pessoas em suas pequenas coisas.

Em Zuloaga como em EV, o interesse das figuras reside não num realismo individual, mas no fato de serem representativas de uma sociedade. EV catava situações pelos vilarejos e cidades de Astúrias: homens do mar conversam junto às redes, comadres fofocam, uma dondoca está rodeada de criados e capelães, notáveis marcham em procissão, obreiros reúnem-se em torno do líder, um jogador de xadrez em seu jogo, um fidalgo camponês com seus cães, seus potros e vacas... Enfim, EV pinta, mais que o homem, o povo. Sabendo o quanto pesa a vida, prefere sobretudo pintar pessoas nos momentos em que escapam à rotina: os obreiros em descanso ou em conversas, os marinheiros no porto, os padres sobre seus cavalos, as mulheres na romaria e todos em efusiva evasão carnavalesca. Diria que EV foi um catador de expressões humanas, como se vê em seus retratos, sempre expressivos e peculiares, enaltecidos por um jogo cromático representativo de aspectos singulares e características psicológicas.

A exposição na sala Iturrioz (1909) será amplamente falada nos círculos culturais de Madrid, criando grandes polêmicas. A crítica estabelece relações diretas com o mestre Goya, sobretudo pela temática empregada. De volta a Paris, EV continua retratando a burguesia. Quando sua carreira parecia estar se consolidando, inesperadamente lhe atravessa o caminho uma doença psíquica, a agorafobia (sensação de angústia em espaços amplos como praças e ruas largas). Volta a Gijón e lá permanece sem conseguir sair de casa.

Pairam dúvidas quanto à real duração do período de reclusão de Evaristo, tanto em suas biografias, quanto em seus próprios depoimentos, indicando que ele mesmo criara uma espécie de mito em torno de sua doença. Aproximadamente, EV passou de 1911 a 1919 em sua casa em Gijón. Evaristo quase não pegava os pincéis, mas não deixou a pintura em absoluto esquecimento. Afinal, produziu obras como o Tríptico (1913). Seus biógrafos constatam o esforço dos amigos em resgatá-lo de sua clausura, incentivando-o a expor. Em 1915 participa de uma exposição coletiva no Real Club Astur de Regatas em Gijón, onde encontramos seis pinturas sem unidade, talvez resultado de uma seleção rapidamente improvisada. É provável que parte das pinturas tenha sido pintada num momento anterior à reclusão. É o caso do retrato de sua avó, pintado por volta de 1910. 
De toda maneira, suas pinturas foram bem recebidas na exposição, sendo as críticas dos principais jornais da cidade (El Comercio e El Noroeste) muito favoráveis ao seu trabalho.

$\mathrm{Na}$ exposição de Belas Artes de Oviedo em 1916, EV apresenta quatro pinturas denominadas de Crepúsculos, pintadas entre os anos 1915-16. Elas se destacam pela sensação proporcionada pelo conjunto cromático, peculiar por sua constituição em camadas grossas e uniformes, característica de grande parte da obra de Evaristo, e também pela sobreposição de camadas aguadas a camadas mais densas, à maneira da aquarela. Estes trabalhos darão início ao seu restabelecimento, um retorno mais constante aos pincéis.

Em 1917 encontramos um artista ativo, com vontade de pintar e notavelmente recuperado da agorafobia. Suas pinturas da época são como esboços, pela dimensão (48 x $39 \mathrm{~cm}$ ) e pelo suporte (cartão). Mas cada uma é preciosa pela riqueza da construção cromática, frescor e espontaneidade: Boda aristocrática, $\mathbf{O}$ palco do gomoso, $\mathbf{O}$ palco da menina loira, $O$ palco familiar, $O$ palco da velha Dama, Elegantes de Gijón, Baile de carnaval. Em 1919 uns amigos o animam a realizar uma exposição em Gijón, da qual sairá outra exposição em Madrid.

\section{O lirismo do olhar}

O primeiro biógrafo de Evaristo, Lafuente Ferrari, num texto para a exposição do Banco Herrero em Oviedo (3 de dezembro de 1997), lembra-nos de uma fala do próprio pintor que nos desvenda uma peculiaridade de sua personalidade artística: "Mais que pintar na tela, gosto de olhar ao infinito e pintar na tela da imaginação".

Pode-se imaginar o quanto sofreu o poeta asturiano das cores em seu período de abulia, em que estava descomposto o circuito que levava da imaginação à ação. Mas EV continuou pintando na tela infinita da imaginação. Ele mesmo expressa, em suas memórias, a emoção que o tomava quando ainda muito jovem saía a pintar a natureza:

Eu ia pintar. Mas ao chegar à própria natureza me embebedava. As paisagens brincavam com meus olhos ao limão [referência ao amarelo intenso do limão espanhol]. Com tanta força e com tanta beleza se sucediam um após o outro, que já mareado de ver, fechei os olhos, e em vez de pintar na tela, pintei na imaginação. Oh!, que pinturas estas as minhas! Não chegará um dia que se possa fazer visíveis os maravilhosos sonhos que nem por assombro alcançam a expressar o pincel e a pena? (Valle, 2000, p.29)

Evaristo não era um copista de paisagens, um repórter do natural, mas sim um artista que se decantava junto ao lirismo da paisagem, a luz, as cores e as figuras que podiam ajudar-lhe a liberar-se desta bebedeira lírica que o possuía diante da natureza. $\mathrm{O}$ que ele captava de uma paisagem, o que mais o atraía era a luz, a emoção da cor no momento lírico, expressáveis com uma determinada gama e relação de tons. Não pintava qualquer paisagem ao acaso, mas só as que deixavam em seu espírito uma impressão profunda e o faziam ruminar lembranças. Como diz Ferrari:

Evaristo Valle não era um pintor normal, era um contemplanubes.4 O hábito dos pintores espanhóis de seu tempo era totalmente oposto: modelo e ateliê. $\mathrm{Na}$ pintura espanhola da época dominaram de modo quase absoluto os pintores nascidos nas vertentes do Mediterrâneo, que de alguma forma impõem seu materialismo sensualista na arte espanhola, seu realismo cru, invocador imediato da presença, ausência de lirismo e intimidade. Ortega y Gasset, educado sob a ardorosa luz de Málaga (Mediterrâneo), mas tendo sido criado nas chamadas

4 Expressão espanhola que designa os sonhadores que olham na direção do infinito, percebendo-o como uma outra dimensão fora deste mundo. 


\begin{abstract}
neblinas germânicas, sente dolorosamente a subserviência do espanhol ao realismo cru e sem poesia. Escrevera Meditações do Quixote com as garras em pé ao modo de arte mediterrânea que busca a áspera ferocidade do presente como tal. Mas o mundo está composto por dois tipos de homens, os meditadores e os sensuais, ou os profundos e os superficiais. Se Sorolla é o grande pintor sensualista que não pode escapar da escravidão ao modelo, da áspera ferocidade do presente, Evaristo Valle, espanhol do cantábrico, está no pólo oposto, ele se apresenta como uma exceção da pintura de seu tempo na Espanha. Acentuadamente diríamos que Evaristo Valle não corresponde aos artistas de seu tempo, porque ele não é um pintor de fantasmagorias e sim de realidades, como mencionava Ortega y Gasset em Meditações do Quixote: “Os gregos são realistas de coisas recordadas e recordar é já idealizar, purificar a cortante aspereza das coisas quando agem sobre nossos sentidos". (1963, p.27)
\end{abstract}

Esse lirismo do olhar participará cada vez mais marcadamente de sua obra pictórica, até as últimas pinturas, produzidas em 1950. Entre 1922-29 realizou exposições importantes em Londres, Nova Iorque e Havana. No entanto, devido a sucessivas crises psíquicas, não conseguia dar uma continuidade a sua carreira. Nos primeiros anos da década de 1930, permaneceu fechado em sua casa, sem sequer conseguir pintar. Em 1934 escreveu uma comédia dramática: O sótão. $5 \mathrm{~A}$ partir de meados desta década, EV retornou à atividade, mantendo uma produção relativamente constante. Carantoña aponta uma série de quadros mais comerciais, obras reminiscentes de obras anteriores, além de alguns lampejos de originalidade, em que retrata a si mesmo caracterizado como personagens históricos ou literários, como Colombo e Quixote (Carantoña, 1986, pp. 129-134). Acrescento, por fim, um dado de grande relevância, que é a presença de obras que refletem seu olhar profundo e sensível sobre a realidade de seu tempo, evidenciando um pintor que atingiu a maturidade em sua arte: As três bruxas (1945), Na fonte (1945), Carnaval Grotesco (1949), O jesuíta (1949) e Homens do Mar (1950).

\title{
Referências bibliográficas
}

ASURI (ed.) (1979). Historia de la pintura. Bilbao: Desclee de Brouwer, Tomos I ao V, ref. I e IV.

BOCKEMÜHL, Michael (1993). J.M.W. Turner: 1775-1851: o mundo da luz e da cor. Berlim:Taschen.

CARANTOÑA, Francisco (1986). Evaristo Valle. Gijón, Fundación Museo E. Valle. FUNDACIÓN MUSEO EVARISTO VALLE (1985). Evaristo Valle, Dibujos. Madrid: Fundación Museo Evaristo Valle, Museo Del Prado, Museo de Bellas Artes de Asturias.

FERRARI, Enrique Lafuente (1963). La vida y el arte de E. Valle. Diputación Provincial de Asturias.

HAUSER, Arnold (1995). História social da Arte e da literatura. São Paulo: Perspectiva. PIÑOLE, N.; VALLE, E. (1998). La mar en un espejo (catálogo da exposição). Gijón: Fundación Museo Evaristo Valle. (2000). Recuerdos da la vida de un pintor. Madrid: Trama Editorial.

\footnotetext{
5 Carantoña descreve esta peça da seguinte maneira: “O sótão é uma obra estranha, onde talvez apareçam algumas preocupações profundas de Evaristo Valle. Um grupo de burgueses é preso, por revolucionários de filiação não explicitada, num imenso sótão. Esperam a morte, entre os prisioneiros predomina a ânsia egoísta da salvação individual sobre qualquer aparente solidariedade que nasce da desgraça comum” (1986, p.115)
} 
WOLHEIM, R. (2000). A pintura como Arte. São Paulo: Cosac Naify.

ZAPICO, F. (1998). E. Valle en la coleción Pedro Masaveu (catálogo da exposicão). Gijón: Fundación Museo Evaristo Valle. 